\title{
Comparison of Cannabinoid $\mathrm{CB}_{1}$ Receptor Binding in Adolescent and Adult Rats: A Positron Emission Tomography Study Using $\left[{ }^{18}\right.$ F] MK-9470
}

\author{
Mathieu Verdurand, ${ }^{1,2}$ Vu Nguyen, ${ }^{2}$ Daniela Stark, ${ }^{2}$ David Zahra, ${ }^{2}$ Marie-Claude Gregoire, ${ }^{2}$ \\ Ivan Greguric, ${ }^{2}$ and Katerina Zavitsanou ${ }^{1,3,4}$
}

${ }^{1}$ Schizophrenia Research Institute, Sydney, Australia

${ }^{2}$ ANSTO LifeSciences, ANSTO, PMB 1 Menai, Sydney, Australia

${ }^{3}$ School of Psychiatry, Faculty of Medicine, University of New South Wales, Sydney, NSW, Australia

${ }^{4}$ Schizophrenia Research Laboratory, Neuroscience Research Australia, Randwick, NSW, Australia

Correspondence should be addressed to Katerina Zavitsanou, k.zavitsanou@neura.edu.au

Received 16 August 2011; Accepted 17 September 2011

Academic Editor: Guy Bormans

Copyright (C) 2011 Mathieu Verdurand et al. This is an open access article distributed under the Creative Commons Attribution License, which permits unrestricted use, distribution, and reproduction in any medium, provided the original work is properly cited.

Despite the important role of cannabinoid $\mathrm{CB}_{1}$ receptors $\left(\mathrm{CB}_{1} \mathrm{R}\right)$ in brain development, little is known about their status during adolescence, a critical period for both the development of psychosis and for initiation to substance abuse. In the present study, we assessed the ontogeny of $\mathrm{CB}_{1} \mathrm{R}$ in adolescent and adult rats in vivo using positron emission tomography with $\left[{ }^{18} \mathrm{~F}\right] \mathrm{MK}-9470$. Analysis of covariance (ANCOVA) to control for body weight that would potentially influence $\left[{ }^{18} \mathrm{~F}\right] \mathrm{MK}-9470$ values between the two groups revealed a main effect of age $(F(1,109)=5.0, P=0.02)$ on $\left[{ }^{18} \mathrm{~F}\right] \mathrm{MK}-9470$ absolute binding (calculated as percentage of injected dose) with adult estimated marginal means being higher compared to adolescents amongst 11 brain regions. This finding was confirmed using in vitro autoradiography with $\left[{ }^{3} \mathrm{H}\right] \mathrm{CP} 55,940(F(10,99)=140.1, P<0.0001)$. This ontogenetic pattern, suggesting increase of $\mathrm{CB}_{1} \mathrm{R}$ during the transition from adolescence to adulthood, is the opposite of most other neuroreceptor systems undergoing pruning during this period.

\section{Introduction}

The endocannabinoid system is a lipid signalling system [1] that appeared early in evolution [2]. It consists of at least two G-protein-coupled cannabinoid receptors $\mathrm{CB}_{1}$ and $\mathrm{CB}_{2}$ $\left(\mathrm{CB}_{1} \mathrm{R}\right.$ and $\left.\mathrm{CB}_{2} \mathrm{R}\right)$ [3], their intrinsic ligands (endocannabinoids) such as $\mathrm{N}$-arachidonoyl ethanolamine (anandamide, AEA) [4] and 2-arachidonoyl glycerol (2-AG) [5], and their associated proteins involved in synthesis, transport, and degradation [6].

The $C_{1} R$, which mediates the psychoactive effects of marijuana, is widely expressed and is considered one of the most abundant G-protein-coupled receptors in the brain. In the central nervous system, endocannabinoids are released from postsynaptic sites and, by activation of the presynaptically located $\mathrm{CB}_{1} \mathrm{R}$ [7], inhibit the release of several neurotransmitters such as GABA, glutamate [8], dopamine, and acetylcholine [9]. In vitro immunohistochemical [10] and autoradiography [11] studies in rats have shown that the $\mathrm{CB}_{1} \mathrm{R}$ is highly expressed in the basal ganglia (lateral caudate-putamen, globus pallidus, entopeduncular nucleus, and substantia nigra pars reticulata), cerebellum (molecular layer), and hippocampus (CA1, CA3, and dentate gyrus molecular layer). Moderate levels are found throughout the cortical regions, whereas low levels are observed in the brainstem (midbrain, pons) and spinal cord.

The $\mathrm{CB}_{1} \mathrm{R}$ has been shown to be involved in various physiological functions like nociception [12], control of movement [13], memory [14], neuroendocrine regulation [15], brain development, and maturation $[16,17]$. Biochemical and functional alterations of $\mathrm{CB}_{1} \mathrm{R}$ have been shown to be implicated in the pathophysiology of distinct neurological 
and psychiatric disorders [18] including schizophrenia [1921]. It is known that cannabis and its derivatives can trigger psychotic-like symptoms in normal individuals [22], and numerous epidemiological studies have demonstrated that consuming cannabis during adolescence (particularly early adolescence) constitutes a risk factor for schizophrenia onset later in life [23-25].

Adolescence is a critical developmental period during the transition from childhood to adulthood. The ages associated with adolescence are commonly considered in humans to be approximately 12 to $20-25$ years of age and postnatal day (PND) 28-55 in rodents [26]. The adolescent brain undergoes both progressive and regressive changes providing the biological basis for the unique adolescent behaviors and their associated changes during maturation to adulthood. At the cellular level, these changes correspond to the marked overproduction of axon and synapses in early puberty and rapid pruning in late adolescence [27]. To date, most developmental studies of the cannabinoid system [28-31] have focused on the embryonic and early postnatal stages. In vitro autoradiographic studies have reported a fivefold increase in $\mathrm{CB}_{1} \mathrm{R}$ density in the brain during postnatal development [32]. $\mathrm{CB}_{1} \mathrm{R}$ capacity in the striatum was doubled between PND 14 and 21. Significant increases in $\mathrm{CB}_{1} \mathrm{R}$ density appeared regionally in the developing brain until PND 21 [32] or PND 30 [33], and the maximum adult level was reached at PND 60 [32]. In contrast, Rodriguez de Fonseca et al. [33] reported slight decreases in binding between PND 30 and 40 and adulthood (PND 70).

Recently, the development of new efficient radiotracers has enabled the study of $\mathrm{CB}_{1} \mathrm{R}$ in vivo using positron emission tomography (PET). Burns et al. [34] demonstrated that the selective, high-affinity inverse agonist for the $\mathrm{CB}_{1} \mathrm{R}$, named $\left[{ }^{18} \mathrm{~F}\right] \mathrm{MK}-9470$ had the potential to be a valuable tool for the in vivo study of $\mathrm{CB}_{1} \mathrm{R}$ biology and pharmacology. Several in vivo preclinical [35-41] and clinical studies [4245 ] have used this compound successfully.

We have recently reported higher levels of dopamine $\mathrm{D}_{1}$ and $\mathrm{D}_{2}$ receptors [46], both serotonin $5 \mathrm{HT}_{1 \mathrm{~A}}$ receptor binding and mRNA expression [47], and $\mathrm{GABA}_{\mathrm{A}}$ receptor binding [48] in adolescent rats (PND 39) compared to adults (PND 70), that is, in accordance with the regressive elimination of synapses and receptors that occurs during the transition from adolescence to adulthood [27]. In the present study, we have undertaken two objectives: first, to demonstrate the feasibility of imaging $\mathrm{CB}_{1} \mathrm{R}$ in vivo in adolescence and adulthood using small animal PET with $\left[{ }^{18} \mathrm{~F}\right] \mathrm{MK}-$ 9470; second, to compare the level of expression/regional distribution of $\mathrm{CB}_{1} \mathrm{R}$ in adolescent and adult rats obtained in vivo with $\mathrm{PET}$ and in vitro with autoradiography using $\left[{ }^{3} \mathrm{H}\right] \mathrm{CP} 55,940$. The aim was to test the hypothesis whether $\mathrm{CB}_{1} \mathrm{R}$ pruning occurs during the transition from adolescence to adulthood as it has been indicated for other neuroreceptor systems.

\section{Materials and Methods}

2.1. Radiochemical Synthesis of $\left[{ }^{18} \mathrm{~F}\right] M K-9470 . \mathrm{CB}_{1} \mathrm{R}$ imaging was performed in all animals using the radioligand $\left[{ }^{18} \mathrm{~F}\right] \mathrm{MK}-9470\left(\mathrm{~N}-\left[2-(3-\right.\right.$ cyanophenyl $)-3-\left(4-\left(2-\left[{ }^{18} \mathrm{~F}\right]\right.\right.$ fluoroethoxy)phenyl)-1-methylpropyl]-2-(5-methyl-2-pyridyloxy)-2-methylpropanamide), a high specificity, high-affinity inverse agonist at the $\mathrm{CB}_{1} \mathrm{R}$. The precursor for radiotracer synthesis and the authentic $\left[{ }^{19} \mathrm{~F}\right] \mathrm{MK}-9470$ standard were obtained from MERCK Research labs (West Point, Pa, USA). Radiolabelling was performed using a two-step semiautomated procedure following the method outlined by Burns et al. [34] with some modifications. In the first step, 2-Bromo- $1\left[{ }^{18} \mathrm{~F}\right]$ fluoroethane $\left(\left[{ }^{18} \mathrm{~F}\right] \mathrm{BrFE}\right)$ was synthesised using a Nuclear Interface FDG synthesizer (GE Medical System). ${ }^{18} \mathrm{~F}$-Fluoroalkylation of the MK-9470 precursor was then manually carried out using $\mathrm{Cs}_{2} \mathrm{CO}_{3}$ as a base. An aliquot of $\left[{ }^{18} \mathrm{~F}\right] \mathrm{BrFE}$ was added, and $\left[{ }^{18} \mathrm{~F}\right] \mathrm{MK}-9470$ was obtained in up to $8 \%$ overall yield (not corrected for decay) after high-performance liquid chromatography (HPLC) and Sep-Pak purification. $\left[{ }^{18} \mathrm{~F}\right] \mathrm{MK}-9470$ product was confirmed by coinjection with the $\left[{ }^{19} \mathrm{~F}\right] \mathrm{MK}-9470$ standard. The final product obtained had a radiochemical purity $>95 \%$ and specific activity averaging $6000 \mathrm{Ci} / \mathrm{mmole}(222 \mathrm{GBq} / \mu$ mole $)$.

2.2. Animals. Male Wistar rats were obtained from the Animal Resource Centre Pty. Ltd (Perth, Australia) and were housed in polyethylene boxes with wire lids $(489 \times 343 \times$ $240 \mathrm{~mm}$ ) in groups of two-three per cage. All handling of animals and procedures was carried out in accordance with the guidelines established by the Animal Care and Ethics Committee at the Australian Nuclear Science and Technology Organisation (ANSTO). The animals were kept at a constant temperature of $22 \pm 2^{\circ} \mathrm{C}$ on a $12-12 \mathrm{~h}$ light-dark cycle with lights on at 9 am and were handled during the seven days preceding the experiment. Food and water were freely available.

The adult cohort consisted of 6 rats with body weights ranging between $381 \pm 22 \mathrm{~g}$ at 10 weeks of age (PND 7072 ), and the adolescent cohort consisted of 6 rats with body weights ranging between $148 \pm 22 \mathrm{~g}$ at 7 weeks of age (PND $35-37)$.

\subsection{In Vivo PET/CT with $\left[{ }^{18} \mathrm{~F}\right] \mathrm{MK}-9470$}

2.3.1. Acquisition and Reconstruction. Animals were fasted for at least 6 hours before the start of the experiment. PET imaging with $\left[{ }^{18} \mathrm{~F}\right] \mathrm{MK}-9470$ was performed with a preclinical PET/CT Inveon (Siemens) system [49]. Anaesthesia was induced by exposing rats to $4 \%$ isoflurane in oxygen and then maintained by reducing the ratio to $1.5-2.5 \%$ for the duration of the studies. Isoflurane anesthesia has been shown not to have any significant effects on absolute $\left[{ }^{18} \mathrm{~F}\right] \mathrm{MK}-9470$ binding as compared to control conditions [36]. The eyes were coated with a lubricating eye ointment (Allergan Inc., Ireland). Body temperature was maintained by a heating pad set at $38^{\circ} \mathrm{C}$ and monitored rectally. Heart rate $(333.2$ \pm 25.9 beats $/ \mathrm{min})$, respiratory rate $(41.6 \pm 9.2$ cycles $/ \mathrm{min})$, and saturation in oxygen $(>95 \%)$ were measured with a pulse oximeter (Starr, Life Sciences Corp, USA). We also monitored the respiratory rate under the CT part of the scanner with a pressure sensor connected to a computer (Biovet, $\mathrm{m} 2 \mathrm{~m}$ imaging crop, USA). After anaesthesia and 
placing of the animal in the scanner with the help of laser guidance, a catheter was placed in a lateral tail vein of the rat and connected to an infusion pump (Harvard Apparatus, USA). A $60 \mathrm{~min}$ PET scan was started at the same time of the start of the one-minute injection of $\left[{ }^{18} \mathrm{~F}\right] \mathrm{MK}-9470$ at a constant tracer mass $(65.2 \pm 1.5$ pmoles $)$. A 15 min CT scan was systematically performed after the PET scan. Activity volumes were reconstructed with an iterative reconstruction (OSEM/MAP) [50] including attenuation and scatter correction, achieving a reconstructed spatial resolution of $1.5 \mathrm{~mm}$.

2.3.2. Data Analysis. A previously developed magneticresonance-imaging- (MRI-)based rat brain atlas was coregistered to the PET volume, using the CT information of the skull (Anatomist/BrainVisa, V3.1.4, http://brainvisa.info/). In detail, all PET acquisitions (12 animals) were coregistered with their respective CT (see Figure 1). All CTs in the adolescent cohort were manually/visually coregistered to one adolescent CT ("adolescence reference CT"). The same methodology was used in the adult group. Finally, the "reference" CTs were manually/visually coregistered to the MRI-based rat brain atlas encompassing eleven volumes of interest (VOI) (Figure 2(a)). Transformation matrixes were then created from the MRI-based rat brain atlas to each PET image in each group.

Previous studies in rats with $\left[{ }^{18} \mathrm{~F}\right] \mathrm{MK}-9470$ have used the last $20 \mathrm{~min}$ of a $60 \mathrm{~min}$ acquisition period (40 to $60 \mathrm{~min}$ ) for quantification purposes [35-37]. In this study, we used percentage of injected dose (activity concentration $(\mathrm{MBq} / \mathrm{mL})$ divided by injected dose $(\mathrm{MBq}))$ of the last 20 minutes of acquisition $\left(\% \mathrm{ID}_{40-60}\right)$ as absolute $\mathrm{CB}_{1} \mathrm{R}$ binding measure.

\subsection{In Vitro Autoradiography with $\left[{ }^{3} \mathrm{H}\right] \mathrm{CP} 55,940$}

2.4.1. Experiments. Twenty-four hours after in vivo imaging, the animals ( 6 adolescents and 5 adults) were euthanized, their brain was dissected, frozen in liquid nitrogen, and stored at $-80^{\circ} \mathrm{C}$. Coronal brain sections $(16 \mu \mathrm{m})$ were cut with a cryostat and thaw-mounted onto microscope slides.

$\left[{ }^{3} \mathrm{H}\right] \mathrm{CP} 55,940$ autoradiography was carried out based on the method previously described in Dalton et al. [51]. All sections were processed simultaneously to minimize experimental variance. On the day of the experiment, sections were taken out of the $-80^{\circ} \mathrm{C}$ freezer and allowed to come to room temperature for approximately $60 \mathrm{~min}$ or until dry. Sections were preincubated for $30 \mathrm{~min}$ at room temperature in $50 \mathrm{mM}$ Tris- $\mathrm{HCl}$ ( $\mathrm{pH}$ 7.4) containing $5 \%$ bovine serum albumin (BSA) in order to equilibrate the tissue to the assay conditions and remove any endogenous ligand. Radioligand binding was measured using single-point saturation analysis which provides a good estimate of receptor density. The $\mathrm{Kd}$ of rat brain $\mathrm{CB}_{1} \mathrm{R}$ has been evaluated at $5.2 \mathrm{nM}$ [11]. In order to ensure saturation of $\mathrm{CB}_{1} \mathrm{R}$, sections were then incubated for $2 \mathrm{~h}$ at room temperature in the same buffer as preincubation with the addition of $10 \mathrm{nM}\left[{ }^{3} \mathrm{H}\right] \mathrm{CP} 55,940$ (specific activity $139.6 \mathrm{Ci} / \mathrm{mmole}$, Perkin Elmer, USA). Nonspecific binding was determined by incubating adjacent sections in the presence of $10 \mu \mathrm{M}$ CP55,940. The concentration of

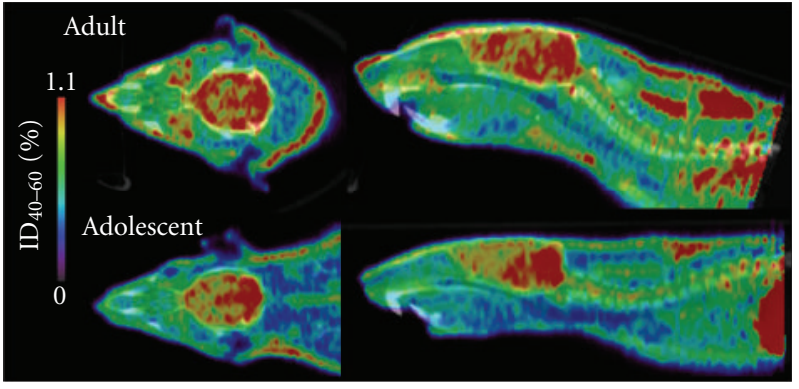

Figure 1: Typical in vivo PET/CT scan images of an adolescent (PND 35-37) and an adult (PND 70-72) Wistar rat in transversal (left) and sagittal (right) planes. For illustration purpose, the absolute binding intensity of $\left[{ }^{18} \mathrm{~F}\right] \mathrm{MK}-9470$ to $\mathrm{CB}_{1} \mathrm{R}\left(\% \mathrm{ID}_{40-60}\right)$ was increased (Anatomist/BrainVisa, V3.1.4, http://brainvisa.info/) in order to reflect the results expressed in estimated marginal means of $\% \mathrm{ID}_{40-60}$, that is, a higher $\mathrm{CB}_{1} \mathrm{R}$ absolute binding in adults compared to adolescents.

$\left[{ }^{3} \mathrm{H}\right] \mathrm{CP} 55,940$ was measured in $10 \mu \mathrm{L}$ aliquots taken from the incubation mixture. After the incubation, sections were washed for $1 \mathrm{~h}$ at $4^{\circ} \mathrm{C}$ in $50 \mathrm{mM}$ Tris- $\mathrm{HCl}(\mathrm{pH}$ 7.4) containing $1 \% \mathrm{BSA}$, and a second wash was then carried out for $3 \mathrm{~h}$ in the same buffer at $4^{\circ} \mathrm{C}$. The third wash was in $50 \mathrm{mM}$ Tris- $\mathrm{HCl}(\mathrm{pH} 7.4)$ for $5 \mathrm{~min}$ at $4^{\circ} \mathrm{C}$. Sections were then dipped briefly in ice cold distilled water and then dried. Dried sections were apposed to Kodak Biomax MR films, together with autoradiographic tritium standards $\left(\left[{ }^{3} \mathrm{H}\right]\right.$ microscales from Amersham), in X-ray film cassettes. Films were developed after 35 days using Kodak GBX developer and fixed with Kodak GBX fixer.

2.4.2. Data Analysis. Films were analysed using a computerassisted image analysis system, Multianalyst, connected to a GS-690 Imaging Densitometer (Bio-Rad, USA). Eleven brain regions of interest (ROI) were manually drawn with the help of a stereotaxic atlas of the rat brain [52] and corresponded to the 11 VOI analysed in vivo (Figure 4). Quantification of receptor binding in each brain region was performed by measuring the average optical density in adjacent brain sections. Nonspecific binding was subtracted to total binding to give a value for specific binding. Optical density measurements for specific binding were then converted into fmoles of $\left[{ }^{3} \mathrm{H}\right] \mathrm{CP} 55,940$ per $\mathrm{mg}$ of tissue equivalent ( $\mathrm{fmol} / \mathrm{mg} \mathrm{TE}$ ) according to the calibration curve obtained from the $\left[{ }^{3} \mathrm{H}\right]$ labelled standards.

2.5. Statistical Analysis. Statistical tests were performed using PASW Statistics (Version 18.0.0) and Graphpad Prism (Version 5.04). Data were analysed for significant outliers $( \pm 2 \mathrm{SD})$, and none were detected. The Kolmogorov-Smirnov test was used to test normality of the data. Parametric tests were used in subsequent analysis since data were normally distributed. The mass and injected dose of $\left[{ }^{18} \mathrm{~F}\right] \mathrm{MK}-9470$ between the adolescent and adult cohorts were compared using unpaired Student's $t$-tests. Pearson correlations were 


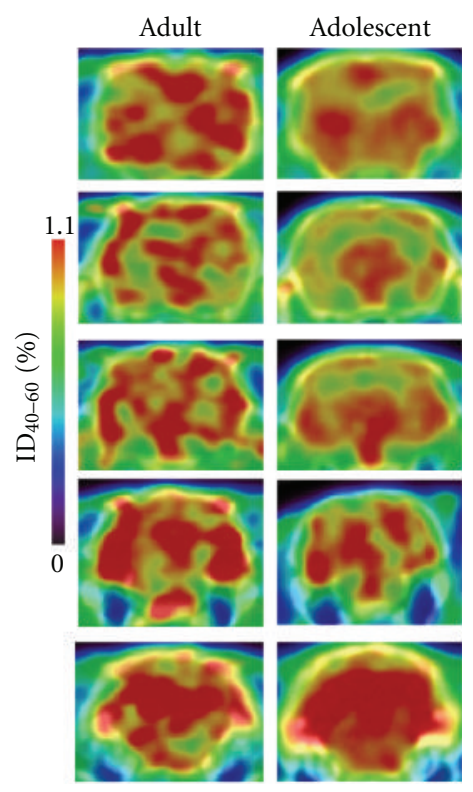

(a)

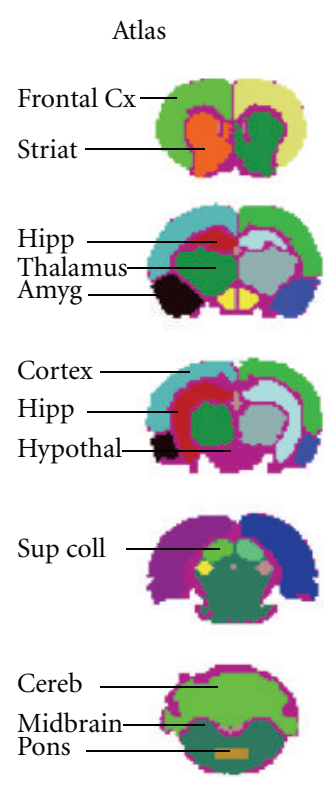

(b)

FIGURe 2: (a) In vivo PET/CT images of $\left[{ }^{18} \mathrm{~F}\right] \mathrm{MK}-9470$ binding $\left(\% \mathrm{ID}_{40-60} \pm \mathrm{SEM}\right)$ at 5 different coronal levels in the adolescent and the adult rat brain. The MRI-based atlas of the rat brain with 11 VOI is shown on the right side of the image. (b) Histograms presenting the adjusted

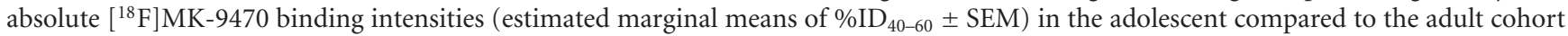
in 11 VOI. Two-way ANCOVA (age $\times$ region) controlling for weight was used to assess statistical significant differences in absolute $\left[{ }^{18} \mathrm{~F}\right] \mathrm{MK}$ 9470 binding between adulthood and adolescence. Statistical analysis revealed that there was a significant $\left({ }^{\#} P<0.05\right.$ significant main effect) increase in $\mathrm{CB}_{1} \mathrm{R}$ absolute binding (44.4\% calculated over $\left.11 \mathrm{VOI}\right)$ in adulthood compared to adolescence. Abbreviations: Striat: striatum; Frtl Cx: frontal cortex; Hipp: hippocampus; Thal: thalamus; Hypothal: hypothalamus; Amyg: amygdala; Sup Coll: superior colliculus; Cereb: cerebellum.

used to examine the relationship between $\% \mathrm{ID}_{40-60}$ and body weight and between $\left[{ }^{18} \mathrm{~F}\right] \mathrm{MK}-9470 \mathrm{CB}_{1} \mathrm{R}$ binding in vivo and $\left[{ }^{3} \mathrm{H}\right] \mathrm{CP} 55,940 \mathrm{CB}_{1} \mathrm{R}$ binding in vitro. Analysis of covariance (ANCOVA) controlling for body weight was used to determine if there was an effect of age and/or region on $\mathrm{CB}_{1} \mathrm{R}$ absolute binding measured in vivo. In vitro data were analysed using two-way ANOVA (age $\times$ region) followed by least significant difference (LSD) tests. Significance was set at $P \leq 0.05$.

\section{Results}

3.1. In Vivo PET with $\left[{ }^{18} F\right] M K$-9470. Adolescent rats showed the regional distribution that corresponds to the previously published regional distribution of $\mathrm{CB}_{1} \mathrm{R}[11,53]$, but adult rats unexpectedly demonstrated a more uniform regional distribution of the PET radioligand (Figures 1 and 2). Cerebellum, striatum, cortical regions, and (moderately) hippocampus showed higher in vivo $\mathrm{CB}_{1} \mathrm{R}$ absolute binding compared to other brain regions. Regions known to have fewer $\mathrm{CB}_{1} \mathrm{R}$ like the thalamus and especially the brainstem (midbrain, pons) presented relatively high $\mathrm{CB}_{1} \mathrm{R}$ absolute binding in vivo (Figure 2).

Time-activity curves (expressed in $\% \mathrm{ID}_{40-60}$ ) showed that $\left[{ }^{18} \mathrm{~F}\right] \mathrm{MK}-9470$ entered the brain with a slow kinetic and reached a peak at approximately $20 \mathrm{~min}$ after-injection.
There were no statistically significant differences in the mass of $\left[{ }^{18} \mathrm{~F}\right] \mathrm{MK}-9470$ injected between the adolescent and adult cohort (mean \pm SEM: $64.8 \pm 1.5 \mathrm{pM}$ and $66.2 \pm$ $2.9 \mathrm{pM}$, resp., $t(10)=0.73, P=0.48)$. No statistical differences were found in the injected doses (ID) $(t(10)=0.56$, $P=0.59)$ between the adolescents $(8.22 \pm 2.07 \mathrm{MBq})$ and the adults $(7.02 \pm 0.59 \mathrm{MBq})$. Animal weights were found to be significantly different $(t(10)=18.16, P<0.0001)$ between adolescent $(148 \pm 9 \mathrm{~g})$ and adult animals $(382 \pm 9 \mathrm{~g})$, and Pearson's correlation showed that weight was strongly and negatively correlated to $\% \mathrm{ID}_{40-60}(r=-0.921, P<$ $0.0001)$. Two-way ANCOVA (age $\times$ region) controlling for weight showed a significant main effect of age $(F(1,109)=$ $4.95, P=0.028$ ) with adults having higher $\mathrm{CB}_{1} \mathrm{R}$ absolute binding compared to adolescents $(+44.4 \%$ over 11 VOI) (Figure 2(b)). A significant effect of region was also found $(F(10,109)=2.41, P=0.012)$. No interaction was observed between age and region $(F(10,109)=0.84, P=0.59)$. Table 1 presents $\mathrm{CB}_{1} \mathrm{R}$ absolute binding levels in adolescents and adults before (unadjusted values) and after controlling for animal body weight (adjusted values).

3.2. In Vitro $\left[{ }^{3} \mathrm{H}\right] \mathrm{CP} 55,940$ Autoradiography. Two-way ANOVA (age $\times$ region) showed a statistically significant main effect of age $(F(1,99)=17.323, P<0.0001)$ with the adults having higher $\mathrm{CB}_{1} \mathrm{R}$ binding than the adolescents 

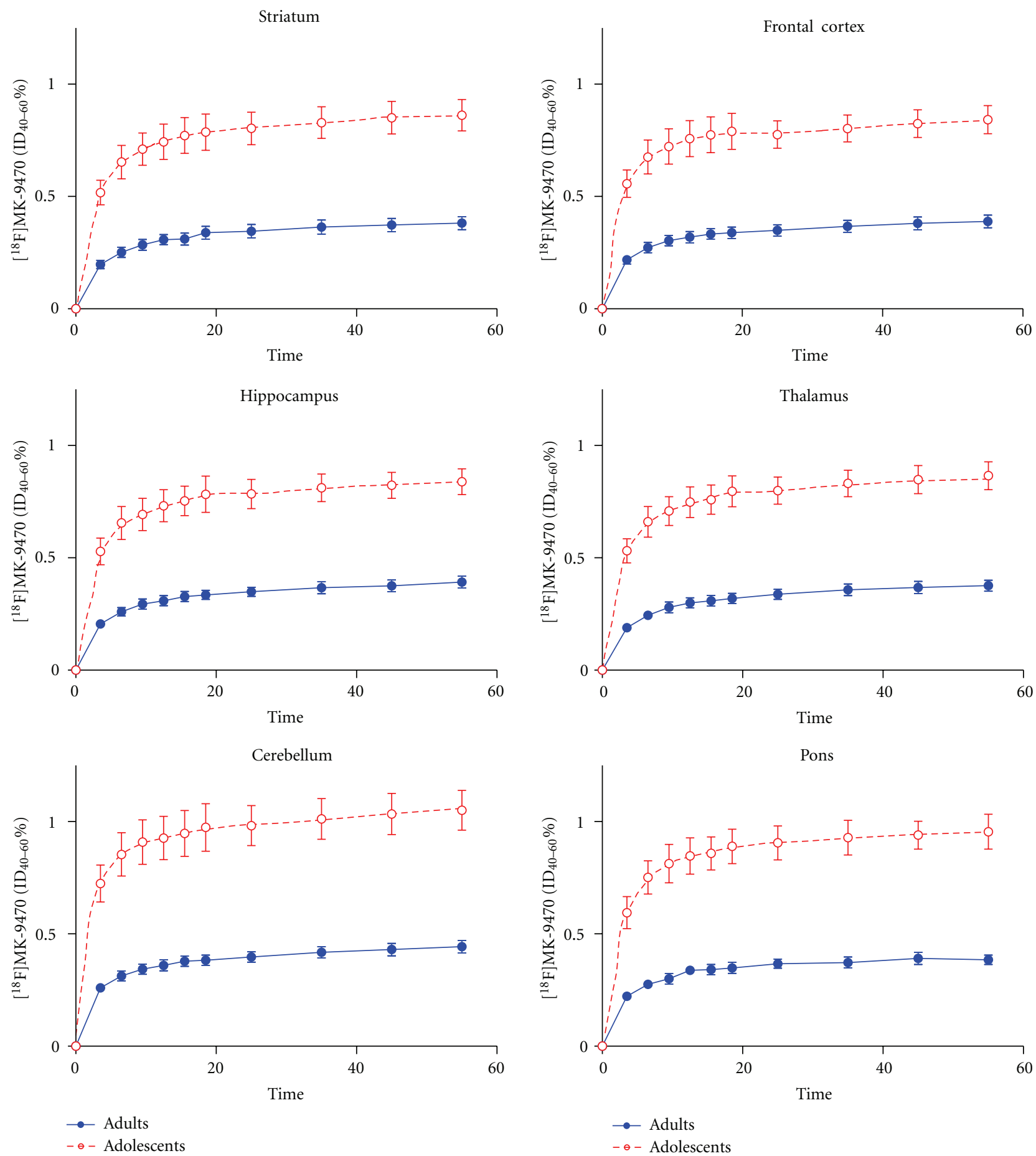

FIgure 3: Time-activity kinetic curves of $\left[{ }^{18} \mathrm{~F}\right] \mathrm{MK}-9470$ expressed in $\% \mathrm{ID}_{40-60} \pm \mathrm{SEM}$ in 6 volumes of interest (VOI), in the adolescent $(n=6)$ (dotted line in red) and the adult $(n=6)$ (plain line in blue) cohort. Note that adolescents' kinetic curves appear higher compared to adults' kinetic curve because values are expressed as $\% \mathrm{ID}_{40-60}$ not taking into account weight as covariate. Estimated marginal means of $\% \mathrm{ID}_{40-60}$ were evaluated in the ANCOVA and showed higher $\left[{ }^{18} \mathrm{~F}\right] \mathrm{MK}-9470$ absolute binding in adults compared to adolescents.

(Figure 4). A significant main effect of region $(F(10,99)=$ $140.1, P<0.0001)$ was also found. No interaction between age and region $(F(10,99)=1.62, P=0.113)$ was observed. The significant main effect of age was further analysed by LSD post hoc tests revealing that $\mathrm{CB}_{1} \mathrm{R}$-specific binding was significantly higher in the adults compared to adolescents in the frontal cortex $(+23.4 \% ; P=0.024)$, the cortex $(+27.1 \% ; P=0.020)$, the hippocampus $(+15.4 \% ; 0.018)$, and the cerebellum $(+15.2 \%, P=0.002)$ (Table 2 and Figure 4). 


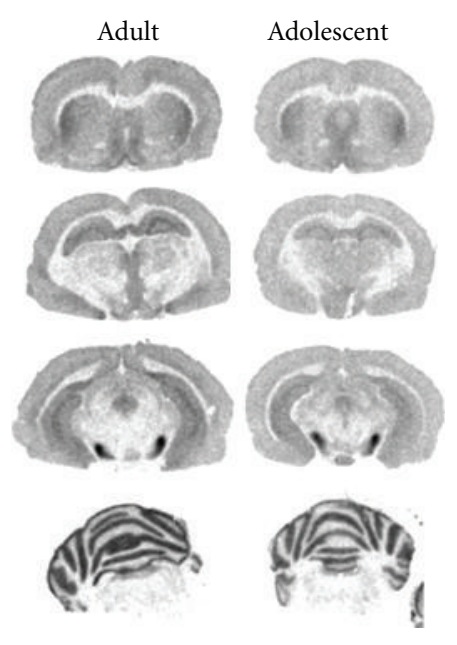

(a)

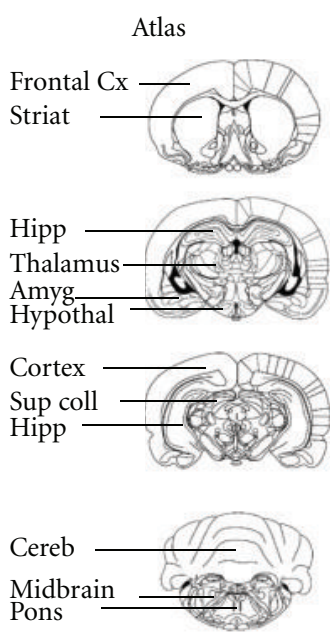

Pons

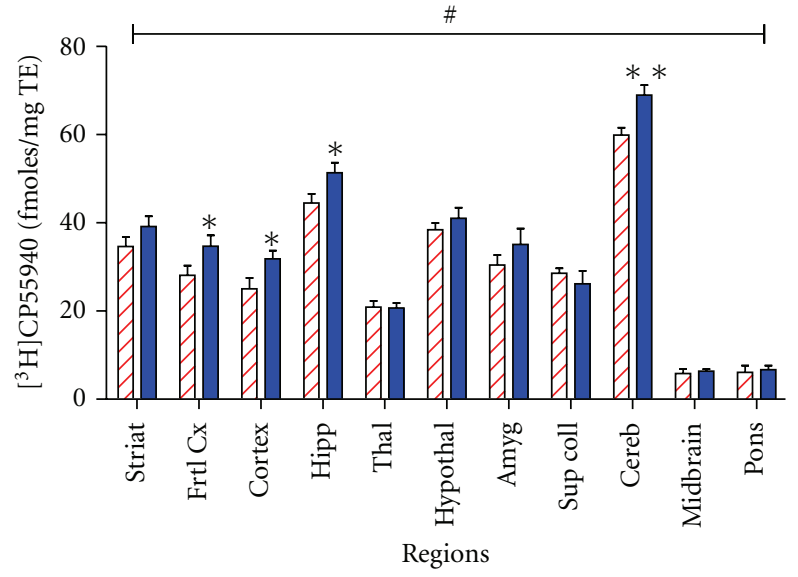

(b)

Figure 4: (a) In vitro autoradiographies of total $\left[{ }^{18} \mathrm{~F}\right] \mathrm{MK}-9470$ binding intensity in coronal sections in an adolescent and an adult rat brain. The atlas of Paxinos and Watson [52] serves as a visual anatomical reference of the 11 brain regions analysed. (b) Histograms of the in vitro specific binding intensities of $\left[{ }^{18} \mathrm{~F}\right] \mathrm{MK}-9470$ (fmoles/mg TE $\pm \mathrm{SEM}$ ) in the adolescent compared to the adult rat brain. Eleven regions of interest were analysed and assessed for statistical significant difference between adolescence and adulthood with two-way ANOVA (age $\times$ region) followed by LSD post hoc tests $\left({ }^{*} P<0.05 ;{ }^{*} P<0.01\right)$. Statistical analysis revealed a significant main effect $\left({ }^{\#} P<0.05\right)$ of age with adults having higher $\mathrm{CB}_{1} \mathrm{R}$ densities than adolescents. The frontal cortex, the cortex, the hippocampus, and the cerebellum showed a statistically significant increase in adults compared to adolescence in the post hoc analysis. Abbreviations: Striat: striatum; Frtl Cx: frontal cortex; Hipp: hippocampus; Thal: thalamus; Hypothal: hypothalamus; Amyg: amygdala; Sup Coll: superior colliculus; Cereb: cerebellum.

TABLE 1: $\mathrm{CB}_{1}$ receptor in vivo binding levels $\left(\left[{ }^{18} \mathrm{~F}\right] \mathrm{MK}-9470\right)$ in adolescents and adults rats.

\begin{tabular}{lccccc}
\hline & \multicolumn{2}{c}{ Adolescents } & \multicolumn{2}{c}{ Adults } & \multirow{2}{*}{ \% change (adjusted) } \\
& Unadjusted & Adjusted & Unadjusted & Adjusted & 50.3 \\
Striatum & $0.86 \pm 0.07$ & $0.49 \pm 0.07$ & $0.38 \pm 0.03$ & $0.74 \pm 0.07$ & 59.8 \\
Frontal cortex & $0.83 \pm 0.06$ & $0.47 \pm 0.07$ & $0.38 \pm 0.03$ & $0.75 \pm 0.07$ & 58.5 \\
Cortex & $0.83 \pm 0.07$ & $0.47 \pm 0.07$ & $0.38 \pm 0.03$ & $0.74 \pm 0.07$ & 59.9 \\
Hippocampus & $0.83 \pm 0.06$ & $0.47 \pm 0.07$ & $0.38 \pm 0.03$ & $0.75 \pm 0.07$ & 49.1 \\
Thalamus & $0.86 \pm 0.06$ & $0.49 \pm 0.07$ & $0.37 \pm 0.03$ & $0.74 \pm 0.07$ & 52.0 \\
Hypothalamus & $0.86 \pm 0.06$ & $0.50 \pm 0.07$ & $0.40 \pm 0.03$ & $0.76 \pm 0.07$ & 63.1 \\
Amygdala & $0.81 \pm 0.06$ & $0.45 \pm 0.07$ & $0.36 \pm 0.03$ & $0.73 \pm 0.07$ & 29.2 \\
Superior colliculus & $0.97 \pm 0.07$ & $0.61 \pm 0.07$ & $0.42 \pm 0.03$ & $0.79 \pm 0.07$ & 18.2 \\
Cerebellum & $1.04 \pm 0.09$ & $0.68 \pm 0.07$ & $0.44 \pm 0.03$ & $0.80 \pm 0.07$ & 38.6 \\
Midbrain & $0.90 \pm 0.06$ & $0.54 \pm 0.07$ & $0.38 \pm 0.02$ & $0.75 \pm 0.07$ & 29.0 \\
pons & $0.95 \pm 0.07$ & $0.58 \pm 0.07$ & $0.39 \pm 0.03$ & $0.75 \pm 0.07$ & \\
\hline
\end{tabular}

Unadjusted values are mean $\% \mathrm{ID}_{40-60} \pm$ SEM; adjusted values are estimated marginal means $\% \mathrm{ID}_{40-60} \pm$ SEM.

Two-way ANCOVA controlling for weight was performed ( $n=6$ per group).

Covariates appearing in the ANCOVA model are evaluated at the following values: weight $=264.9142$.

3.3. Correlation between $\left[{ }^{18} \mathrm{~F}\right] \mathrm{MK}-9470 C B_{1} R$ Binding In Vivo and $\left[{ }^{3} \mathrm{H}\right] \mathrm{CP} 55,940 \mathrm{CB}_{1} \mathrm{R}$ Binding In Vitro. Correlations were not statistically significant between absolute $\mathrm{CB}_{1} \mathrm{R}$ binding evaluated with $\left[{ }^{18} \mathrm{~F}\right] \mathrm{MK}-9470$ in vivo and specific $\mathrm{CB}_{1} \mathrm{R}$ binding calculated with $\left[{ }^{3} \mathrm{H}\right] \mathrm{CP} 55,940$ in vitro, $(r=0.1816$, $P=0.41)$.

\section{Discussion}

In the present study, we used two complementary techniques to examine potential developmental differences in $\mathrm{CB}_{1} \mathrm{R}$ binding in the brain of adolescent and adult rats. After controlling for body weight, $\mathrm{CB}_{1} \mathrm{R}$ absolute binding measured in vivo with PET and $\left[{ }^{18} \mathrm{~F}\right] \mathrm{MK}-9470$ was significantly higher in the adult animals compared to adolescents over 11 brain regions. This finding was confirmed in vitro with autoradiography and $\left[{ }^{3} \mathrm{H}\right] \mathrm{CP} 55,940$.

Noteworthy, the percentage of increase observed in the adult compared to the adolescent cohort with the 2 complementary techniques was not of the same magnitude (44\% in vivo versus $11 \%$ in vitro over the 11 regions of interest), and no significant correlation was found between 
TABLE 2: $\mathrm{CB}_{1}$ receptor in vitro binding levels $\left(\left[{ }^{3} \mathrm{H}\right] \mathrm{CP} 55,940\right)$ in adolescents and adults rats.

\begin{tabular}{|c|c|c|c|c|}
\hline & Adolescents & Adults & $\%$ change & $P$ value \\
\hline Striatum & $34.62 \pm 2.18$ & $39.13 \pm 2.38$ & 13.0 & 0.117 \\
\hline Frontal cortex & $28.12 \pm 2.21$ & $34.68 \pm 2.51$ & 23.4 & 0.024 \\
\hline Cortex & $25.02 \pm 2.49$ & $31.81 \pm 1.86$ & 27.1 & 0.020 \\
\hline Hippocampus & $44.51 \pm 2.03$ & $51.36 \pm 2.26$ & 15.4 & 0.018 \\
\hline Thalamus & $20.90 \pm 1.41$ & $20.70 \pm 1.16$ & -0.9 & 0.946 \\
\hline Hypothalamus & $38.46 \pm 1.53$ & $41.01 \pm 2.40$ & 6.6 & 0.376 \\
\hline Amygdala & $30.41 \pm 2.29$ & $35.09 \pm 3.62$ & 15.4 & 0.106 \\
\hline Superior colliculus & $28.58 \pm 1.12$ & $26.16 \pm 2.93$ & -8.5 & 0.400 \\
\hline Cerebellum & $59.89 \pm 1.66$ & $68.98 \pm 2.23$ & 15.2 & 0.002 \\
\hline Midbrain & $5.86 \pm 0.96$ & $6.35 \pm 0.51$ & 8.4 & 0.864 \\
\hline Pons & $6.12 \pm 1.50$ & $6.70 \pm 0.92$ & 9.5 & 0.840 \\
\hline
\end{tabular}

Two-way ANOVA followed by LSD post hoc test.

Data expressed as mean $\mathrm{fmol} / \mathrm{mg} \mathrm{TE} \pm \mathrm{SEM} ; n=6$ per group.

the data obtained with the two techniques. The comparison between in vitro and in vivo results (no correlation) and the apparent discrepancies may relate to a number of factors.

Firstly, methodological issues of data analysis should be considered. The percentage of injected dose (\% ID) that we used here gives an absolute index of binding in vivo. This means that it reflects specific and nonspecific binding in the brain, radioligand present in the brain blood circulation, and possible radioactive metabolites crossing the blood-brain barrier. We did not calculate standardised uptake values (absolute index normalising for weight) because it would have biased our results as our two groups had significantly different weight means. Also, the absence of a brain region devoid of $\mathrm{CB}_{1} \mathrm{R}$ prevented us from implementing a simplified reference tissue model. We chose to use an atlasbased analysis of our data, with predefined VOI, over a statistical parametric mapping approach because we wanted to compare the same regions with the in vivo and in vitro methodologies. To our knowledge, the metabolism of $\left.{ }^{18} \mathrm{~F}\right] \mathrm{MK}-9470$ in the male (adult and adolescent) rat brain has not been assessed; therefore, the presence of active metabolites that cross the blood-brain barrier cannot be ruled out. Indeed, a metabolite is likely to cross the bloodbrain barrier of adult female Wistar rats (Casteels et al., oral communication). Radiometabolites produced in adults (but not in adolescents) could potentially cross the blood brain barrier, affect the \%ID we calculated, and in turn contribute to the uniform regional distribution of the PET radioligand we observed in adults compared to adolescents (Figures 1 and 2). Differences in radioligand present in the brain blood circulation (e.g., difference in blood flow) between the adolescent and adult cohorts that would have affected our measures cannot be ruled out either. To be in line with previous studies in rats with $\left[{ }^{18} \mathrm{~F}\right] \mathrm{MK}-9470[35-$ 37], we have used the last $20 \mathrm{~min}$ of a $60 \mathrm{~min}$ acquisition period (40 to $60 \mathrm{~min}$ ) for quantification purposes. A recent study however indicated that the distribution volume $\left(V_{T}\right)$ of $\left[{ }^{18} \mathrm{~F}\right] \mathrm{MK}-9470$ as quantitative outcome evaluated by full kinetic modelling was reasonably correlated with standardised uptake values between 60 and $80 \mathrm{~min}$ (Casteels et al., oral communication, 2011). Longer acquisitions periods (at least $80 \mathrm{~min}$ ) in future studies using this radioligand would ensure that equilibrium is reached.

The second factor that could explain discrepancies between in vitro and in vivo results is the drug phenotype. Indeed, $\left[{ }^{18} \mathrm{~F}\right] \mathrm{MK}-9470$ is an inverse agonist at $\mathrm{CB}_{1} \mathrm{R}$ [34], whereas $\left[{ }^{3} \mathrm{H}\right] \mathrm{CP} 55,940$ is an agonist at both $\mathrm{CB}_{1} \mathrm{R}$ and $\mathrm{CB}_{2} \mathrm{R}[54,55]$. The concentration of $\mathrm{CB}_{2} \mathrm{R}$ in the rat brain is supposed to be small in comparison to $\mathrm{CB}_{1} \mathrm{R}[3,56$, 57]. Thus, $\left[{ }^{3} \mathrm{H}\right] \mathrm{CP} 55,940$ binding in the brain will mainly reflect $\mathrm{CB}_{1} \mathrm{R}$. Inverse agonists will preferentially bind to receptors uncoupled from their G-protein, whereas agonists will preferentially bind to receptors that are coupled to their G-protein [58]. This means that in vivo we would have preferentially bound $\mathrm{CB}_{1} \mathrm{R}$ uncoupled to their G-protein, whereas in vitro the G-protein-coupled ones would have been targeted. In vitro assays typically reflect all receptors that are available to bind to radioligand, whereas in vivo, only a subset of these receptors are available to bind to radioligand since some may be compartmentalised, some in a low affinity state and some occupied by endogenous ligand [59].

Finally, another factor affecting the comparison between in vitro and in vivo measures is the difference in concentration of the radioligand used. Theory of PET experiment is based upon the injection of a radioligand at tracer concentration that is not supposed to trigger any biological effect. In order to meet this requirement, the radioligand should not bind to more than $5-10 \%$ of the total receptors concentration $\left(B_{\max }\right)$ [59]. Based on previously reported $B_{\max }$ in rat brain $(0.5-1.1 \mathrm{pmol} / \mathrm{mg}$ prot) [11], we calculated that the mass of ligand needed to be approximately $0.1-0.7$ nmoles. On the other hand, quantitative in vitro autoradiography studies need saturation of the available binding sites (at least 3 times greater than the $K_{\mathrm{d}}$ ). Thus, by saturating a different proportion of receptors in vivo and in vitro, differential outcomes must be cautiously interpreted.

Our main results, showing an increase in $\mathrm{CB}_{1} \mathrm{R}$ in adults (PND 70-72) compared to adolescents (PND 3537 ) in vivo and in vitro, are in accordance with in vitro studies that have looked at $\mathrm{CB}_{1} \mathrm{R}$ expression over time 
in development. Belue and collaborators [32] have found significant regional increases in the numbers of $\mathrm{CB}_{1} \mathrm{R}\left(B_{\max }\right)$ in the developing rat brain (PND 0, 7, 14, 21, and 60) using in vitro autoradiography with $\left[{ }^{3} \mathrm{H}\right] \mathrm{CP} 55,940$. Although $\mathrm{CB}_{1} \mathrm{R}$ density was not measured during adolescence, this study suggested that $\mathrm{CB}_{1} \mathrm{R}$ binding continuously increased until the maximum adult level was reached at PND 60. They observed that cortical regions (mainly posterior cortex) and hippocampus showed a statistically significant increase in binding between PND 21 and PND 60 [32]. According to the authors, the increase in $\mathrm{CB}_{1} \mathrm{R}$ could be an indication of either an increased differentiation of neurones into cells harbouring $\mathrm{CB}_{1} \mathrm{R}$ or an induction of the expression of $\mathrm{CB}_{1} \mathrm{R}$ in cells already differentiated. Another in vitro study using the same radioligand $\left(\left[{ }^{3} \mathrm{H}\right] \mathrm{CP} 55,940\right)$ showed that $\mathrm{CB}_{1}$ Rs are transiently expressed in white matter areas during embryonic and early postnatal periods, progressively "shift" to their adult localization at PND 30, and increase between PND 30 and adulthood in the hippocampus, nucleus accumbens, and cerebral cortex [53]. In addition, Ellgren et al. [60] reported an increase in $\mathrm{CB}_{1} \mathrm{R}$ protein expression in the nucleus accumbens shell and no changes in prefrontal cortex between mid-(PND 38) and late-(PND 49) adolescence.

In humans, an in vitro study found an increase in $\mathrm{CB}_{1} \mathrm{R}$ density between children/infant age $(n=5,3$ months to 8 years old) and adults ( $n=5,22$ to 73 years old) in frontal cortex, hippocampus CA1 and DG, caudate putamen, globus pallidus, and cerebellum [61]. Interestingly, a recent PET study using $\left[{ }^{18} \mathrm{~F}\right] \mathrm{MK}-9470$ found an increase in $\mathrm{CB}_{1} \mathrm{R}$ binding in the basal ganglia, lateral temporal cortex, and limbic system of aged female but not male humans [62]. Another PET study using $\left[{ }^{11} \mathrm{C}\right] \mathrm{OMAR}$ in healthy males showed an age-associated decline in $\mathrm{CB}_{1} \mathrm{R}$ volume of distribution that was significant in globus pallidus only [63]. To allow comparison with other studies from our group [46, 51 ], we chose to evaluate the ontogeny of $\mathrm{CB}_{1} \mathrm{R}$ in adolescent and adult male rodents. Recent experiments have shown that female Wistar rats presented a high $\sim 35-39 \%$ intersubject variability in $\mathrm{CB}_{1} \mathrm{R}$ binding evaluated as $\left[{ }^{18} \mathrm{~F}\right] \mathrm{MK}-9470$ standard uptake values between 60 and 80 minutes (Casteels et al., oral communication, 2011). Intersubject variability in our study with males only was of $17 \%$ in the adult group and $18 \%$ in the adolescent group. Future in vivo animal studies looking at the ontogeny of $\mathrm{CB}_{1} \mathrm{R}$ in female rats as well as during aging would help in clarifying the relationships between gender, aging, and the endocannabinoid system Figure 3.

In the mammalian brain, synapses and receptors within most regions are overproduced and eliminated during two phases of life. The first one occurs just before birth, after completion of the brain innervation, and witnesses the apoptosis (programmed cell death) of $50 \%$ of neurones in order to increase efficiency of synaptic transmission $[64,65]$. The second one occurs during the periadolescence period with a tremendous overproduction of synapses and receptors followed by their progressive elimination or pruning [27]. This pattern of expression-overproduction followed by elimination-is shared among mammalian brains and part of a fundamental developmental strategy called "functional validation" [27]. Teicher et al. [66] reported an overproduction of $D_{1}$ and $D_{2}$ from PND 25 to 40 followed by a pruning to reach adulthood [66]. We have recently reported higher levels of dopamine $\mathrm{D}_{1}$ and $\mathrm{D}_{2}$ receptors [46], both serotonin $5 \mathrm{HT}_{1 \mathrm{~A}}$ receptor binding and mRNA expression [47], and $\mathrm{GABA}_{\mathrm{A}}$ receptor binding [48] in adolescent rats (PND 39) compared to adults (PND 70) that is in line with the regressive elimination of synapses and receptors that occurs during the transition from adolescence to adulthood. In contrast, the results of the present study indicate that $\mathrm{CB}_{1} \mathrm{Rs}$ are not undergoing a dramatic elimination between adolescence (PND 35-37) and adulthood (PND 70-72) and continue to increase, at least until PND 70-72. Our study does not rule out the possibility that the $\mathrm{CB}_{1} \mathrm{Rs}$ are undergoing pruning at a later developmental "aging" stage. Possible explanations for the observed upregulation in adult rats can be hypothesised. Since a homeostatic and modulatory role is attributed to endocannabinoids [57], the $\mathrm{CB}_{1} \mathrm{R}$ upregulation could be related to a compensation of functional losses in other monaminergic or GABAergic systems. In addition, changes in $\mathrm{CB}_{1} \mathrm{R}$ may reflect changes in endocannabinoid markers such as AEA and 2-AG. Limited information is available regarding endogenous cannabinoid ligands levels during the transition from adolescence to adulthood; however, a recent study has shown an increase of AEA but not 2-AG levels from early to late adolescence in the prefrontal cortex of the rats [60]. Studies looking at the developmental profile of endocannabinoid ligands in different brain regions and their correlations with $\mathrm{CB}_{1} \mathrm{R}$ levels would help in elucidating the developmental and morphogenic roles of this system during the transition from adolescence to adulthood.

\section{Conclusion}

The present study demonstrated the feasibility of imaging $\mathrm{CB}_{1} \mathrm{R}$ in vivo with $\mathrm{PET}$ and $\left[{ }^{18} \mathrm{~F}\right] \mathrm{MK}-9470$ in adolescent and adult rats. Our results suggest that $\mathrm{CB}_{1}$ Rs are increased during the transition from adolescence (PND 35-37) to adulthood (PND 70-72), a pattern that is opposite of most other neuroreceptor systems that have already started undergoing pruning during this time window. Availability of new radioligands such as $\left[{ }^{18} \mathrm{~F}\right] \mathrm{MK}-9470$ in combination with PET would offer a unique opportunity to gain insights into the role of the endocannabinoid system during critical stages of development using longitudinal and within-subjects experimental designs and understand the consequences of its alterations after pharmacological challenges as well as in neurodevelopmental animal models of psychosis.

\section{Acknowledgments}

Merck \& Co., Inc. is acknowledged for the availability of the $\left[{ }^{18} \mathrm{~F}\right] \mathrm{MK}-9470$ precursor and standard. This work is supported by the Schizophrenia Research Institute (SRI), Australia, utilizing infrastructure funding from NSW Health and by an internal Australian Nuclear Science and Technology Organisation Senior Research Fellowship to K. Zavitsanou. 


\section{References}

[1] V. Di Marzo, A. Fontana, H. Cadas et al., "Formation and inactivation of endogenous cannabinoid anandanide in central neurons," Nature, vol. 372, no. 6507, pp. 686-691, 1994.

[2] J. M. McPartland, "Phylogenomic and chemotaxonomic analysis of the endocannabinoid system," Brain Research Reviews, vol. 45, no. 1, pp. 18-29, 2004.

[3] A. C. Howlett, F. Barth, T. I. Bonner et al., "International union of pharmacology. XXVII. Classification of cannabinoid receptors," Pharmacological Reviews, vol. 54, no. 2, pp. 161202, 2002.

[4] W. A. Devane, L. Hanus, A. Breuer et al., "Isolation and structure of a brain constituent that binds to the cannabinoid receptor," Science, vol. 258, no. 5090, pp. 1946-1949, 1992.

[5] R. Mechoulam, S. Ben-Shabat, L. Hanuš et al., "Identification of an endogenous 2-monoglyceride, present in canine gut, that binds to cannabinoid receptors," Biochemical Pharmacology, vol. 50, no. 1, pp. 83-90, 1995.

[6] D. Piomelli, "The molecular logic of endocannabinoid signalling," Nature Reviews Neuroscience, vol. 4, no. 11, pp. 873884, 2003.

[7] R. I. Wilson and R. A. Nicoll, "Neuroscience: endocannabinoid signaling in the brain," Science, vol. 296, no. 5568, pp. 678-682, 2002.

[8] S. C. Azad, M. Eder, G. Marsicano, B. Lutz, W. Zieglgänsberger, and G. Rammes, "Activation of the cannabinoid receptor type 1 decreases glutamatergic and GABAergic synaptic transmission in the lateral amygdala of the mouse," Learning and Memory, vol. 10, no. 2, pp. 116-128, 2003.

[9] G. L. Gessa, M. Melis, A. Muntoni, and M. Diana, "Cannabinoids activate mesolimbic dopamine neurons by an action on cannabinoid CB1 receptors," European Journal of Pharmacology, vol. 341, no. 1, pp. 39-44, 1998.

[10] K. Tsou, K. Mackie, M. C. Sañudo-Peña, and J. M. Walker, "Cannabinoid $\mathrm{CB} 1$ receptors are localized primarily on cholecystokinin-containing GABAergic interneurons in the rat hippocampal formation," Neuroscience, vol. 93, no. 3, pp. 969-975, 1999.

[11] M. Herkenham, A. B. Lynn, M. R. Johnson, L. S. Melvin, B. R. De Costa, and K. C. Rice, "Characterization and localization of cannabinoid receptors in rat brain: a quantitative in vitro autoradiographic study," Journal of Neuroscience, vol. 11, no. 2, pp. 563-583, 1991.

[12] V. Di Marzo and L. D. Petrocellis, "Plant, synthetic, and endogenous cannabinoids in medicine," Annual Review of Medicine, vol. 57, pp. 553-574, 2006.

[13] J. Fernandez-Ruiz and S. Gonzales, "Cannabinoid control of motor function at the basal ganglia," Handbook of Experimental Pharmacology, no. 168, pp. 479-507, 2005.

[14] G. Riedel and S. N. Davies, "Cannabinoid function in learning, memory and plasticity," Handbook of Experimental Pharmacology., no. 168, pp. 445-477, 2005.

[15] J. Tasker, "Endogenous cannabinoids take the edge off neuroendocrine responses to stress," Endocrinology, vol. 145, no. 12, pp. 5429-5430, 2004.

[16] J. J. Fernandez-Ruiz, F. Berrendero, M. L. Hernandez, J. Romero, and J. A. Ramos, "Role of endocannabinoids in brain development," Life Sciences, vol. 65, no. 6-7, pp. 725-736, 1999.

[17] T. Harkany, E. Keimpema, K. Barabas, and J. Mulder, "Endocannabinoid functions controlling neuronal specification during brain development," Molecular and Cellular Endocrinology, vol. 286, no. 1-2, supplement 1, pp. S84-S90, 2008.
[18] D. Parolaro, N. Realini, D. Vigano, C. Guidali, and T. Rubino, "The endocannabinoid system and psychiatric disorders," Experimental Neurology, vol. 224, no. 1, pp. 3-14, 2010.

[19] B. Dean, S. Sundram, R. Bradbury, E. Scarr, and D. D. Copolov, "Studies on [3H]CP-55940 binding in the human central nervous system: regional specific changes in density of cannabinoid-1 receptors associated with schizophrenia and cannabis use," Neuroscience, vol. 103, no. 1, pp. 9-15, 2001.

[20] K. Zavitsanou, T. Garrick, and X. F. Huang, "Selective antagonist [3H]SR141716A binding to cannabinoid CB1 receptors is increased in the anterior cingulate cortex in schizophrenia," Progress in Neuro-Psychopharmacology and Biological Psychiatry, vol. 28, no. 2, pp. 355-360, 2004.

[21] V. S. Dalton, L. E. Long, C. S. Weickert, and K. Zavitsanou, "Paranoid schizophrenia is characterized by increased $\mathrm{CB}$ 1 receptor binding in the dorsolateral prefrontal cortex," Neuropsychopharmacology, vol. 36, no. 8, pp. 1620-1630, 2011.

[22] D. T. Malone, M. N. Hill, and T. Rubino, "Adolescent cannabis use and psychosis: epidemiology and neurodevelopmental models," British Journal of Pharmacology, vol. 160, no. 3, pp. 511-522, 2010.

[23] L. Arseneault, M. Cannon, R. Poulton, R. Murray, A. Caspi, and T. E. Moffitt, "Cannabis use in adolescence and risk for adult psychosis: iongitudinal prospective study," British Medical Journal, vol. 325, no. 7374, pp. 1212-1213, 2002.

[24] S. Zammit, P. Allebeck, S. Andreasson, I. Lundberg, and G. Lewis, "Self reported cannabis use as a risk factor for schizophrenia in Swedish conscripts of 1969: historical cohort study," British Medical Journal, vol. 325, no. 7374, pp. 11991201, 2002.

[25] N. C. Stefanis, P. Delespaul, C. Henquet, C. Bakoula, C. N. Stefanis, and J. Van Os, "Early adolescent cannabis exposure and positive and negative dimensions of psychosis," Addiction, vol. 99, no. 10, pp. 1333-1341, 2004.

[26] L. P. Spear, "The adolescent brain and age-related behavioral manifestations," Neuroscience and Biobehavioral Reviews, vol. 24, no. 4, pp. 417-463, 2000.

[27] S. L. Andersen, "Trajectories of brain development: point of vulnerability or window of opportunity?" Neuroscience and Biobehavioral Reviews, vol. 27, no. 1-2, pp. 3-18, 2003.

[28] F. Berrendero, N. Sepe, J. A. Ramos, V. Di Marzo, and J. J. Fernandez-Ruiz, "Analysis of cannabinoid receptor binding and mRNA expression and endogenous cannabinoid contents in the developing rat brain during late gestation and early postnatal period," Synapse, vol. 33, no. 3, pp. 181-191, 1999.

[29] J. Fernandez-Ruiz, F. Berrendero, M. L. Hernandez, and J. A. Ramos, "The endogenous cannabinoid system and brain development," Trends in Neurosciences, vol. 23, no. 1, pp. 1420, 2000.

[30] A. Perez-Rosado, J. Manzanares, J. Fernandez-Ruiz, and J. A. Ramos, "Prenatal $\Delta$ 9-tetrahydrocannabinol exposure modifies proenkephalin gene expression in the fetal rat brain: sexdependent differences," Brain Research Developmental Brain Research, vol. 120, no. 1, pp. 77-81, 2000.

[31] K. K. Ade and D. M. Lovinger, "Anandamide regulates postnatal development of long-term synaptic plasticity in the rat dorsolateral striatum," Journal of Neuroscience, vol. 27, no. 9, pp. 2403-2409, 2007.

[32] R. C. Belue, A. C. Howlett, T. M. Westlake, and D. E. Hutchings, "The ontogeny of cannabinoid receptors in the brain of postnatal and aging rats," Neurotoxicology and Teratology, vol. 17, no. 1, pp. 25-30, 1995.

[33] F. Rodriguez de Fonseca, J. A. Ramos, A. Bonnin, and J. J. Fernandez-Ruiz, "Presence of cannabinoid binding sites in the 
brain from early postnatal ages," NeuroReport, vol. 4, no. 2, pp. 135-138, 1993.

[34] H. D. Burns, K. Van Laere, S. Sanabria-Bohorquez et al., “ $\left[{ }^{18} \mathrm{~F}\right] \mathrm{MK}-9470$, a positron emission tomography (PET) tracer for in vivo human PET brain imaging of the cannabinoid-1 receptor," Proceedings of the National Academy of Sciences of the United States of America, vol. 104, no. 23, pp. 9800-9805, 2007.

[35] K. Goffin, G. Bormans, C. Casteels et al., "An in vivo $\left[{ }^{18} \mathrm{~F}\right] \mathrm{MK}-$ 9470 microPET study of type 1 cannabinoid receptor binding in Wistar rats after chronic administration of valproate and levetiracetam," Neuropharmacology, vol. 54, no. 7, pp. 1103 1106, 2008.

[36] C. Casteels, G. Bormans, and K. Van Laere, "The effect of anaesthesia on $\left[{ }^{18} \mathrm{~F}\right] \mathrm{MK}-9470$ binding to the type 1 cannabinoid receptor in the rat brain," European Journal of Nuclear Medicine and Molecular Imaging, vol. 37, no. 6, pp. 1164-1173, 2010.

[37] C. Casteels, B. Vanbilloen, D. Vercammen et al., "Influence of chronic bromocriptine and levodopa administration on cerebral type 1 cannabinoid receptor binding," Synapse, vol. 64, no. 8, pp. 617-623, 2010.

[38] C. Casteels, E. Lauwers, A. Baitar, G. Bormans, V. Baekelandt, and K. Van Laere, "In vivo type 1 cannabinoid receptor mapping in the 6-hydroxydopamine lesion rat model of Parkinson's disease," Brain Research, vol. 1316, pp. 153-162, 2010.

[39] N. Gerard, J. Ceccarini, G. Bormans et al., "Influence of chronic nicotine administration on cerebral type 1 cannabinoid receptor binding: an in vivo micro-pet study in the rat using $\left[{ }^{18}\right.$ F]MK-9470," Journal of Molecular Neuroscience, vol. 42, no. 2, pp. 162-167, 2010.

[40] C. Casteels, C. Vandeputte, J. R. Rangarajan et al., "Metabolic and type 1 cannabinoid receptor imaging of a transgenic rat model in the early phase of Huntington disease," Experimental Neurology, vol. 229, no. 2, pp. 440-449, 2011.

[41] C. Casteels, E. Martinez, G. Bormans et al., "Type 1 cannabinoid receptor mapping with $\left[{ }^{18} \mathrm{~F}\right] \mathrm{MK}-9470$ PET in the rat brain after quinolinic acid lesion: a comparison to dopamine receptors and glucose metabolism," European Journal of Nuclear Medicine and Molecular Imaging, vol. 37, no. 12, pp. 2354-2363, 2010.

[42] K. Van Laere, M. Koole, S. M. S. Bohorquez et al., "Wholebody biodistribution and radiation dosimetry of the human cannabinoid type-1 receptor ligand ${ }^{18} \mathrm{~F}-\mathrm{MK}-9470$ in healthy subjects," Journal of Nuclear Medicine, vol. 49, no. 3, pp. 439445, 2008.

[43] S. M. Sanabria-Bohorquez, T. G. Hamill, K. Goffin et al., "Kinetic analysis of the cannabinoid-1 receptor PET tracer [ $\left.{ }^{18} \mathrm{~F}\right] \mathrm{MK}-9470$ in human brain," European Journal of Nuclear Medicine and Molecular Imaging, vol. 37, no. 5, pp. 920-933, 2010.

[44] K. Van Laere, K. Goffin, G. Bormans et al., "Relationship of type 1 cannabinoid receptor availability in the human brain to novelty-seeking temperament," Archives of General Psychiatry, vol. 66, no. 2, pp. 196-204, 2009.

[45] N. Gerard, G. Pieters, K. Goffin, G. Bormans, and K. Van Laere, "Brain type 1 cannabinoid receptor availability in patients with anorexia and bulimia nervosa," Biological Psychiatry, vol. 70, no. 8, pp. 777-784, 2011.

[46] V. S. Dalton and K. Zavitsanou, "Differential treatment regimen-related effects of cannabinoids on D1 and D2 receptors in adolescent and adult rat brain," Journal of Chemical Neuroanatomy, vol. 40, no. 4, pp. 272-280, 2010.
[47] K. Zavitsanou, H. Wang, V. S. Dalton, and V. Nguyen, "Cannabinoid administration increases 5HT1A receptor binding and mRNA expression in the hippocampus of adult but not adolescent rats," Neuroscience, vol. 169, no. 1, pp. 315-324, 2010.

[48] M. Verdurand, V. S. Dalton, and K. Zavitsanou, "GABA $A$ receptor density is altered by cannabinoid treatment in the hippocampus of adult but not adolescent rats," Brain Research, vol. 1351, pp. 238-245, 2010.

[49] Q. Bao, D. Newport, M. Chen, D. B. Stout, and A. F. Chatziioannou, "Perfrmance evalution of the inveon dedicated PET preclinical tomograph based on the NEMA NU-4 standards," Journal of Nuclear Medicine, vol. 50, no. 3, pp. 401-408, 2009.

[50] J. Qi, R. M. Leahy, S. R. Cherry, A. Chatziioannou, and T. H. Farquhar, "High-resolution 3D bayesian image reconstruction using the microPET small-animal scanner," Physics in Medicine and Biology, vol. 43, no. 4, pp. 1001-1013, 1998.

[51] V. S. Dalton, H. Wang, and K. Zavitsanou, "HU210induced downregulation in cannabinoid CB1 receptor binding strongly correlates with body weight loss in the adult rat," Neurochemical Research, vol. 34, no. 7, pp. 1343-1353, 2009.

[52] G. Paxinos and C. Watson, The Rat Brain in Stereotaxic Coordinates, vol. 6, Academic Press, 2007.

[53] J. Romero, E. Garcia-Palomero, F. Berrendero et al., "Atypical location of cannabinoid receptors in white matter areas during rat brain development," Synapse, vol. 26, no. 3, pp. 317-323, 1997.

[54] R. G. Pertwee, "Pharmacology of cannabinoid receptor ligands," Current Medicinal Chemistry, vol. 6, no. 8, pp. 635-664, 1999.

[55] J. L. Wiley, R. L. Barrett, J. Lowe, R. L. Balster, and B. R. Martin, "Discriminative stimulus effects of CP 55,940 and structurally dissimilar cannabinoids in rats," Neuropharmacology, vol. 34, no. 6, pp. 669-676, 1995.

[56] B. K. Atwood and K. MacKie, "CB2: a cannabinoid receptor with an identity crisis," British Journal of Pharmacology, vol. 160, no. 3, pp. 467-479, 2010.

[57] V. Di Marzo, M. Bifulco, and L. De Petrocellis, "The endocannabinoid system and its therapeutic exploitation," Nature Reviews Drug Discovery, vol. 3, no. 9, pp. 771-784, 2004.

[58] S. S. Negus, "Some implications of receptor theory for in vivo assessment of agonists, antagonists and inverse agonists," Biochemical Pharmacology, vol. 71, no. 12, pp. 1663-1670, 2006.

[59] R. B. Innis, V. J. Cunningham, J. Delforge et al., "Consensus nomenclature for in vivo imaging of reversibly binding radioligands," Journal of Cerebral Blood Flow and Metabolism, vol. 27, no. 9, pp. 1533-1539, 2007.

[60] M. Ellgren, A. Artmann, O. Tkalych et al., "Dynamic changes of the endogenous cannabinoid and opioid mesocorticolimbic systems during adolescence: THC effects," European Neuropsychopharmacology, vol. 18, no. 11, pp. 826-834, 2008.

[61] S. Mato, E. Del Olmo, and A. Pazos, "Ontogenetic development of cannabinoid receptor expression and signal transduction functionality in the human brain," European Journal of Neuroscience, vol. 17, no. 9, pp. 1747-1754, 2003.

[62] K. Van Laere, K. Goffin, C. Casteels et al., "Genderdependent increases with healthy aging of the human cerebral cannabinoid-type 1 receptor binding using $\left[{ }^{18} \mathrm{~F}\right] \mathrm{MK}-9470$ PET," NeuroImage, vol. 39, no. 4, pp. 1533-1541, 2008.

[63] D. F. Wong, H. Kuwabara, A. G. Horti et al., "Quantification of cerebral cannabinoid receptors subtype 1 (CB1) in healthy subjects and schizophrenia by the novel PET radioligand 
[11C]OMAR," NeuroImage, vol. 52, no. 4, pp. 1505-1513, 2010.

[64] J. P. Changeux and A. Danchin, "Selective stabilisation of developing synapses as a mechanism for the specification of neuronal networks," Nature, vol. 264, no. 5588, pp. 705-712, 1976.

[65] D. Purves and J. W. Lichtman, "Elimination of synapses in the developing nervous system," Science, vol. 210, no. 4466, pp. 153-157, 1980.

[66] M. H. Teicher, S. L. Andersen, and J. C. Hostetter, "Evidence for dopamine receptor pruning between adolescence and adulthood in striatum but not nucleus accumbens," Developmental Brain Research, vol. 89, no. 2, pp. 167-172, 1995. 


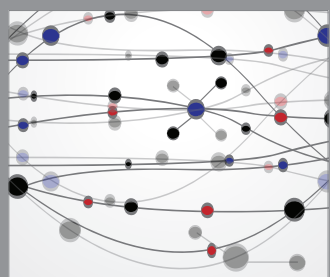

The Scientific World Journal
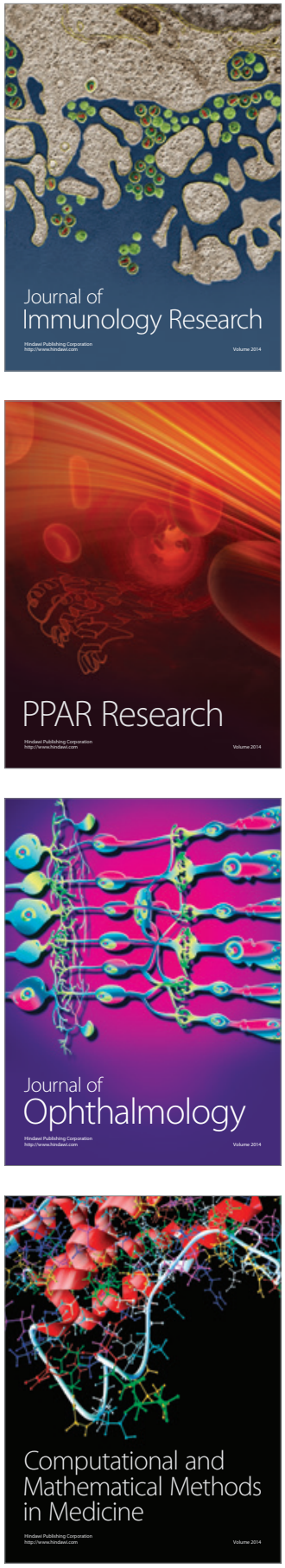

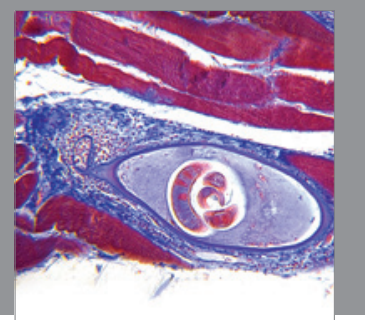

Gastroenterology

Research and Practice
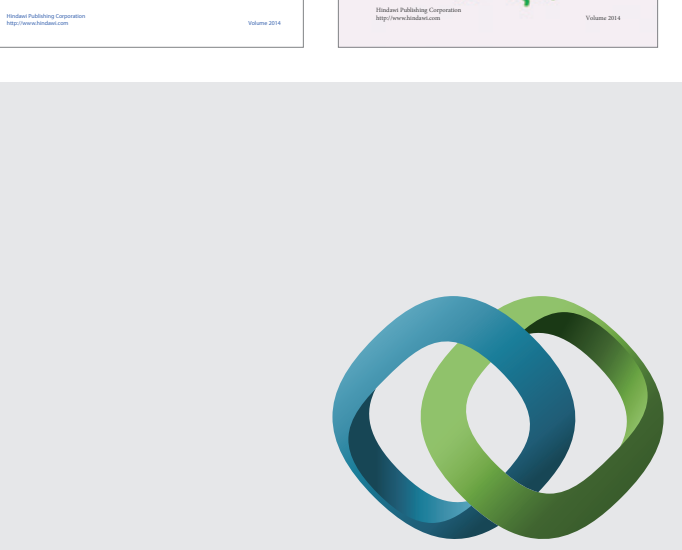

\section{Hindawi}

Submit your manuscripts at

http://www.hindawi.com
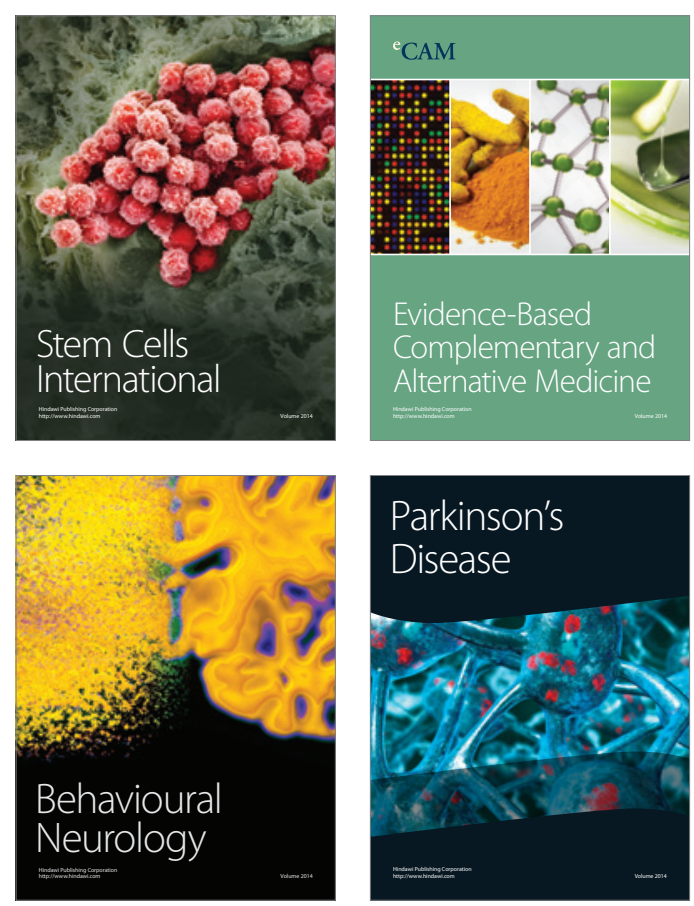

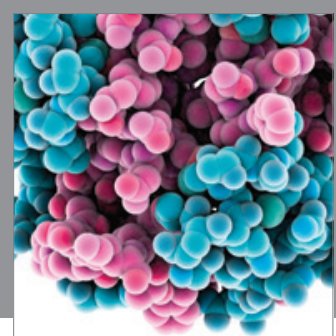

Journal of
Diabetes Research

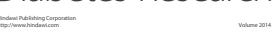

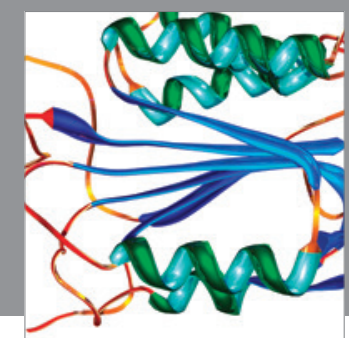

Disease Markers
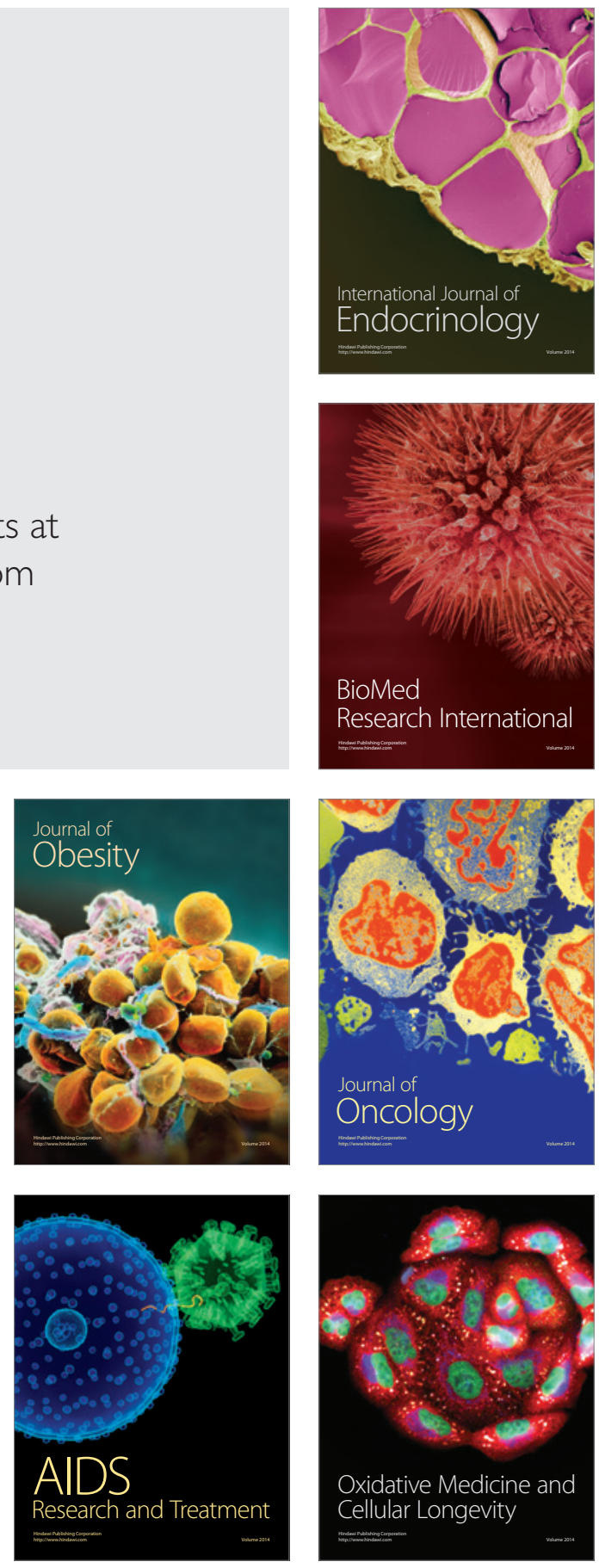